\title{
EFFECT OF SINTERING TEMPERATURE ON MECHANICAL PROPERTIES OF
}

\section{Mg-Zr ALLOY}

\author{
T. JUDSON DURAI ${ }^{1}$, M. SIVAPRAGASH ${ }^{2}$ \& M. EDWIN SAHAYARAJ ${ }^{3}$ \\ ${ }^{I}$ Assistant Professor, Department of Mechanical Engineering, Noorul Islam University, \\ Kumaracoil, Kanyakumari district, Tamil Nadu, India \\ ${ }^{2}$ Dean, Department of Mechanical Engineering, V.V. College of Engineering, \\ Thisayanvilai, Thirunelveli district, Tamil Nadu, India \\ ${ }^{3}$ Associate Professor, Department of Automobile Engineering, Noorul Islam University,
}

Kumaracoil, Kanyakumari district, Tamil Nadu, India

\begin{abstract}
Magnesium, Zirconium alloy is developed in three different sintering temperatures through powder metallurgy technique followed by hot extrusion in this work. The application of this material is for orthopedic implants. Magnesium alloy result shows improvement in density, hardness, tensile strength and minimized porosity on increasing sintering temperature. The surface characterization of the alloy is carried out through optical microscopy. The SEM (Scanning Electron Microscope) analysis of fractured surface of Mg alloy shows quasi-cleavage fracture.

KEYWORDS: Mg Alloy, Powder Metallurgy \& Tensile Strength
\end{abstract}

Received: Jul 30, 2017; Accepted: Aug 18, 2017; Published: Sep 02, 2017; Paper Id.: IJMPERDOCT201713

\section{INTRODUCTION}

Magnesium alloys are crucial for bio-medical applications [1] in orthopedics, due to their possible use as biodegradable implants. The human body metabolism needs 250-300 mg, of Mg ions daily [2]. Pure magnesium and its alloys are becoming much sought after than other alloys because of their light weight strength ratio behaviors. Further, $\mathrm{Mg}$ alloys used for other applications may not be biocompatible, within the human body. The reason may be that, some elements in the degradation process have toxicity and create complications. To overcome these drawbacks, novel magnesium alloys can be developed using non-toxicity and biocompatible elements [3]. The element zirconium has been identified as a possible candidate, being biocompatible as well as having grain refining properties that, considerably improve the mechanical strength and corrosion resistance of the alloy generated. In $0.73 \mathrm{wt} \%$ of $\mathrm{Mg}, \mathrm{Zr}$ is having very low solid solubility, and it has also been acknowledged as there are no intermetallic phases, which are formed between $\mathrm{Zr}$ and $\mathrm{Mg}$ [4]. The addition of $\mathrm{Zr}$ yields better biocompatibility and osseo integration than titanium in both in vitro and in vivo studies [5, 6].

Powder metallurgy (PM) is a competitor to some other methods, due to cost effective and large scale production of complicated components. Material improvements can be made in most cases, through this technology [7]. Effective sintering can improve the powders bonding and reduce porosity. In addition, the mechanical properties of the alloy are enhanced. However, no studies have been reported on the effect of varying sintering temperatures, on mg-zr alloy. The effect of sintering temperature on mg-zr alloy, fabricated through 
powder metallurgy followed by hot extrusion and its mechanical properties are investigated in this work. Moreover, metallurgical characterizations are discussed.

\section{MATERIALS AND METHODS}

\section{Sample Preparation}

The powders of magnesium and zirconium were bought from MEPCO Metal Powder Company, India. The samples of Mg-Zr alloy were formed in the chemical composition (in wt. \%) of $99.5 \mathrm{Mg} / 0.5 \mathrm{Zr}$. The powders were mixed properly, according to their respective weight at $350 \mathrm{rpm}$, for $1 \mathrm{hr}$ in ball mill. The mixed powder was used to form billets of sizes $30 \mathrm{~mm}$ height and $50 \mathrm{~mm}$ diameter, using compacting pressure of $690 \mathrm{Mpa}$. An aluminum foil was used to cover the compacted billets, to prevent any reaction with oxygen from the atmosphere, and then the samples were sintered in argon environment at $450^{\circ} \mathrm{C}, 500^{\circ} \mathrm{C}$, and $550^{\circ} \mathrm{C}$, in a muffle furnace for $1 \mathrm{hr}$, respectively. The samples were then extruded in argon atmosphere at $350^{\circ} \mathrm{C}$, to form a cylindrical rod of $13 \mathrm{~mm}$ diameter and $400 \mathrm{~mm}$ length. The colloidal graphite was used as lubricant for extrusion at the ratio of 15:1, using 150 ton vertical hydraulic press. The rods were heat-treated for 15 minutes in an argon atmosphere at $260^{\circ} \mathrm{C}$ to relieve their stresses [8] followed by cutting to make $10 \mathrm{~mm}$ diameter and $10 \mathrm{~mm}$ length.

\section{Optical Microscopy}

The micro structural characterization study was conducted using MVHD-1000 AP/MP, Shanghoui Dahens Optics and Fine Mechanics Co. Ltd., digital micro hardness tester. The finer grades of emery papers 800, 1000,1200,1500,2000 were used for polishing the samples of $\mathrm{Mg}$ alloy. Further, dish polishing machine was used to polish by adding diamond paste of $0.2,0.4,0.6 \mu \mathrm{m}$. Then, the standard metallographic technique was used to chemically etch the polished samples. The chemicals used to prepare the etchant were 20-ml of glacial acetic acid, 10-ml of methanol, 50-ml of picric acid, and 10-ml of deionized water. The deionized water and ethanol were used to wash etched surface [9].

\section{Density and Porosity Measurement}

The Archimedes principle was used to find the porosity and density of the samples. For the measurement distilled water was used as immersion fluid and the digital type physical balance, as a weighing machine.

\section{Micro Hardness Measurement}

The digital micro-hardness tester was used to measure Vickers micro-hardness (VHV), using a pyramidal diamond indenter. The included angle is $136^{\circ}$; indenting load is $25 \mathrm{gf}$; the rate of indentation is $60 \mu \mathrm{m} / \mathrm{s}$; dwell time is $20 \mathrm{~s}$; major applied load is $15 \mathrm{~kg}$. All these standards are taken according to the ASTM E18-94 standards.

\section{Tensile Testing}

The standard ASTM E8-01 was used to determine the tensile properties of Mg alloys. An automated 10 ton servo hydraulic testing machine was used to conduct a test, on the round tensile test specimen of gauge length $76.2 \mathrm{~mm}$ and diameter $4.74 \mathrm{~mm}$ with the strain rate of $0.300 \mathrm{~mm} / \mathrm{min}$. The load-displacement curve was used to plot engineering stressstrain curves.

\section{Fracture Behavior}

The tensile fracture surface of $\mathrm{Mg}$ alloy specimen has been taken, to perform fractural characterization analysis. 
JSM-6610LV SEM was used to conduct fractural studies.

\section{RESULTS AND DISCUSSIONS}
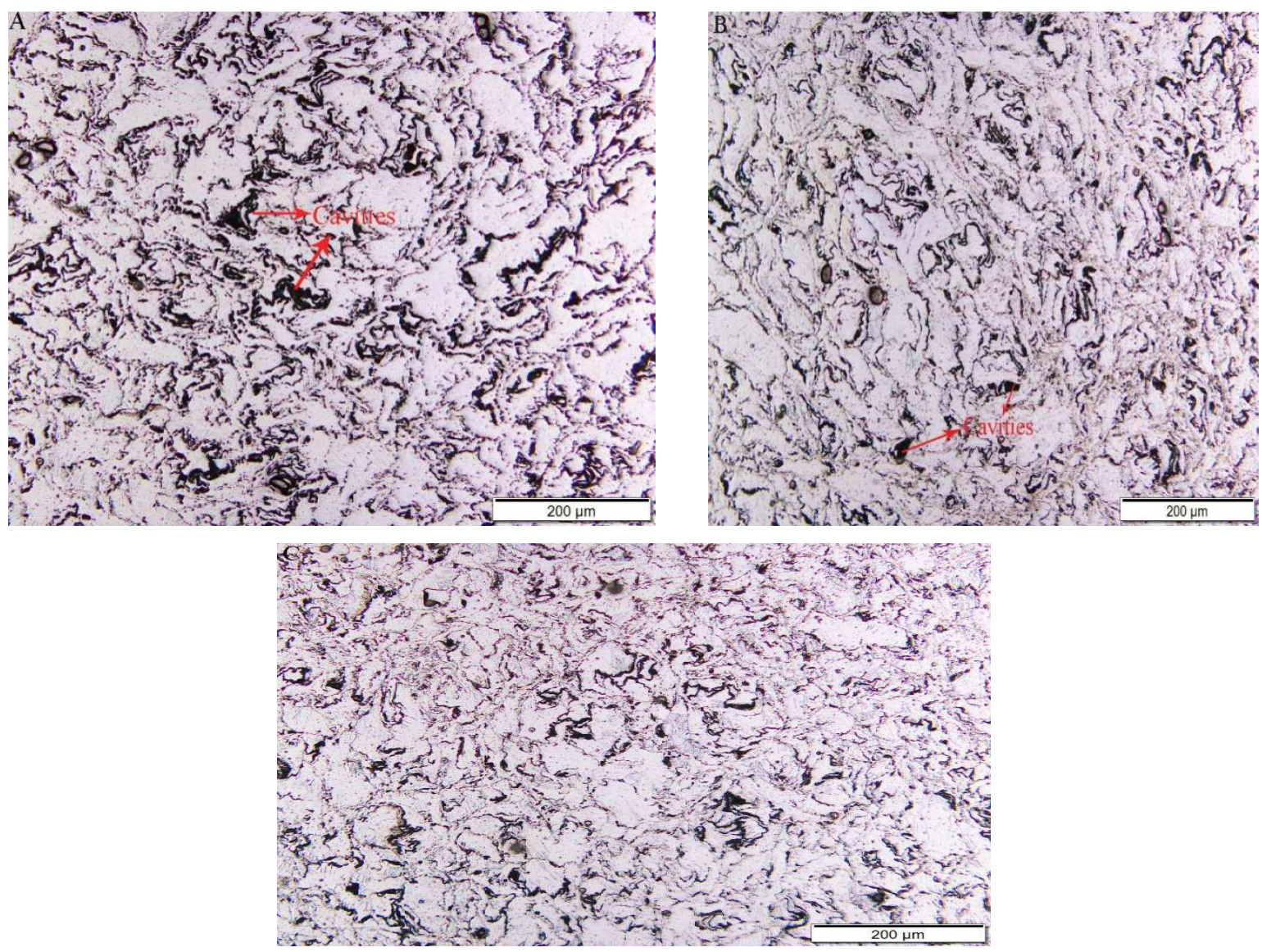

Figure 1: Microstructures of Mg-Zr Alloy of Varying Sintering Temperatures (A) $450^{\circ} \mathrm{C}$, (B) $500^{\circ} \mathrm{C},(\mathrm{C}) 550^{\circ} \mathrm{C}$

The microstructures observed at100X magnification of Mg-Zr alloys, are shown in Figure 1 (A, B, C) for the sintering temperatures $450^{\circ} \mathrm{C}, 500^{\circ} \mathrm{C}$ and $550^{\circ} \mathrm{C}$, respectively. All these microstructures appear to have pores and cavities. Due to the increase of sintering temperatures, the cavities are reduced as shown in figure 1(A-C). This could be due to the re crystallization of alloy, to the enhancement of grain refinement that occurs and the cavities formed during compaction are filled, by grain deformation during the extrusion process.

The hardness results of $\mathrm{Mg}-\mathrm{Zr}$ alloys are shown in figure 2. The results of porosity and density measurements conducted on the sintered $\mathrm{Mg}$ alloy, are given in Table1.The values of hardness exhibited the micro hardness, that was raised because of the increasing sintering temperature of the $\mathrm{Mg}$ alloy. The crystallite sizes of $\mathrm{Mg}$ and $\mathrm{Zr}$ of size $32 \mu \mathrm{m}$ and $24 \mu \mathrm{m}$ are used to develop an $\mathrm{Mg}-\mathrm{Zr}$ alloy. The increasing sintering temperature refines the grains of both $\mathrm{Mg}$ and $\mathrm{Zr}$. The very fine grains of $\mathrm{Mg}$ are gained, at the sintering temperature $550^{\circ} \mathrm{C}$. This temperature is nearer to the melting temperature of $\mathrm{Mg}$ of $650^{\circ} \mathrm{C}$. For that reason, the grain deformation might be terminated, and the formed finer grains fill the cavities. As a result, the homogeneity of the alloy system develops so as to reduce porosity. The reduction in cavity and porosity, enhances the density and hardness of $\mathrm{Mg}$ alloy. When the post-sintering process of extrusion takes place, pores 
are removed due to a reduction in the mechanical property of porosity. Minimal oxidation of magnesium and absence of macro pores happens with the features of density [10].

Table 1: Density and Porosity Measurement Results

\begin{tabular}{|c|c|c|c|c|}
\hline Specimen & Temperature/ ${ }^{\circ} \mathbf{C}$ & $\begin{array}{c}\text { Theoretical Density } \\
(\boldsymbol{\rho} \text { th }) \mathbf{g} / \mathbf{c m}^{\mathbf{3}}\end{array}$ & $\begin{array}{c}\text { Experimental } \\
\text { Density }(\boldsymbol{\rho} \mathbf{e x}) \mathbf{g} / \mathbf{c m}^{\mathbf{3}}\end{array}$ & Porosity \% \\
\hline $\mathrm{Mg} / 0.5 \mathrm{wt} \% \mathrm{Zr}$ & $450^{\circ} \mathrm{C}$ & 1.7639 & 1.7092 & 0.37 \\
\hline $\mathrm{Mg} / 0.5 \mathrm{wt} \% \mathrm{Zr}$ & $500^{\circ} \mathrm{C}$ & 1.7639 & 1.7462 & 0.35 \\
\hline $\mathrm{Mg} / 0.5 \mathrm{wt} \% \mathrm{Zr}$ & $550^{\circ} \mathrm{C}$ & 1.7639 & 1.7528 & 0.32 \\
\hline
\end{tabular}

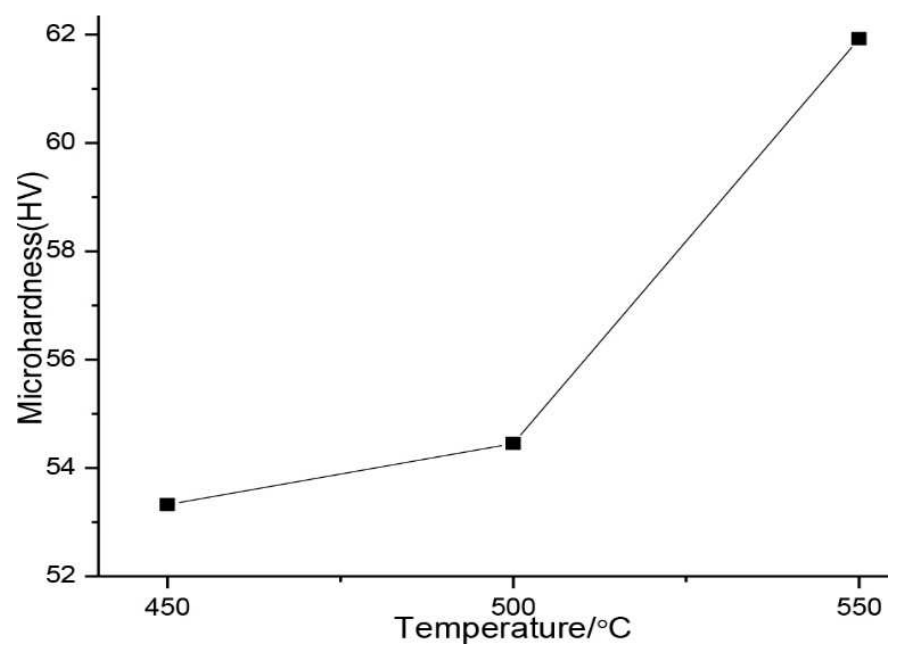

Figure 2: Hardness of $\mathrm{Mg}-\mathrm{Zr}$ alloy of Varying Sintering Temperatures (A) $450^{\circ} \mathrm{C}$, (B) $500^{\circ} \mathrm{C}$, (C) $550^{\circ} \mathrm{C}$

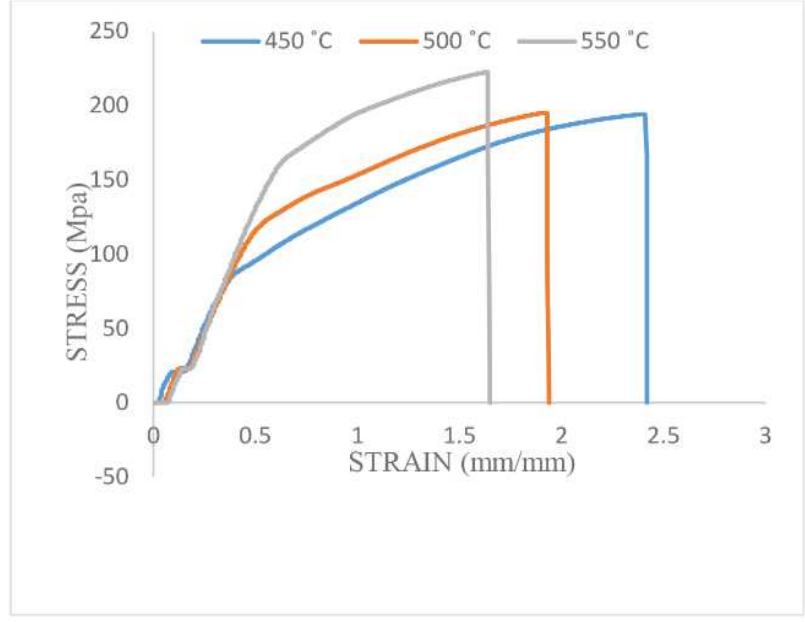

Figure 3: Tensile Stress Strain Curve of Mg-Zr Alloy of Varying Sintering Temperatures (A) $450^{\circ} \mathrm{C},(B) 500^{\circ} \mathrm{C}$, (C) $550^{\circ} \mathrm{C}$

The tensile stress-strain behaviors, of Mg alloy are shown in Fig 3. The tensile properties of the Mg alloy samples taken, for consideration reveal a concurrent increase in properties. Increase in overall mechanical properties is observed, with increasing sintering temperatures. Reduction in porosity form leads, to the increase in tensile strength and all these happen, because of increasing sintering temperatures. Factors affecting mechanical properties to a good extent are grain size, Orowans strengthening and necessary dislocations [11]. 
Generally, the strength of alloy materials is increased by dispersing solid particles into the matrix [12]. It is observed that, $\mathrm{Mg} / 0.5 \mathrm{Zr}$ alloy exhibits superior mechanical properties of ultimate tensile strength, at $550^{\circ} \mathrm{C}$ sintering temperature. The improved properties are attributed to effective transfer of load to the alloy.

The various tensile fracture surfaces of the alloy samples are shown in Figure 4. The reports stretch when fracture occurs in Mg alloy, which is quasi-cleavage fracture or ductile cleavage fracture [13]. Figure 4(A-C) shows mixture of brittle and plastic deformation, which leads to cause quasi-cleavage fracture. Some secondary cracks are also observed, and this may be occurred due to brittle nature.
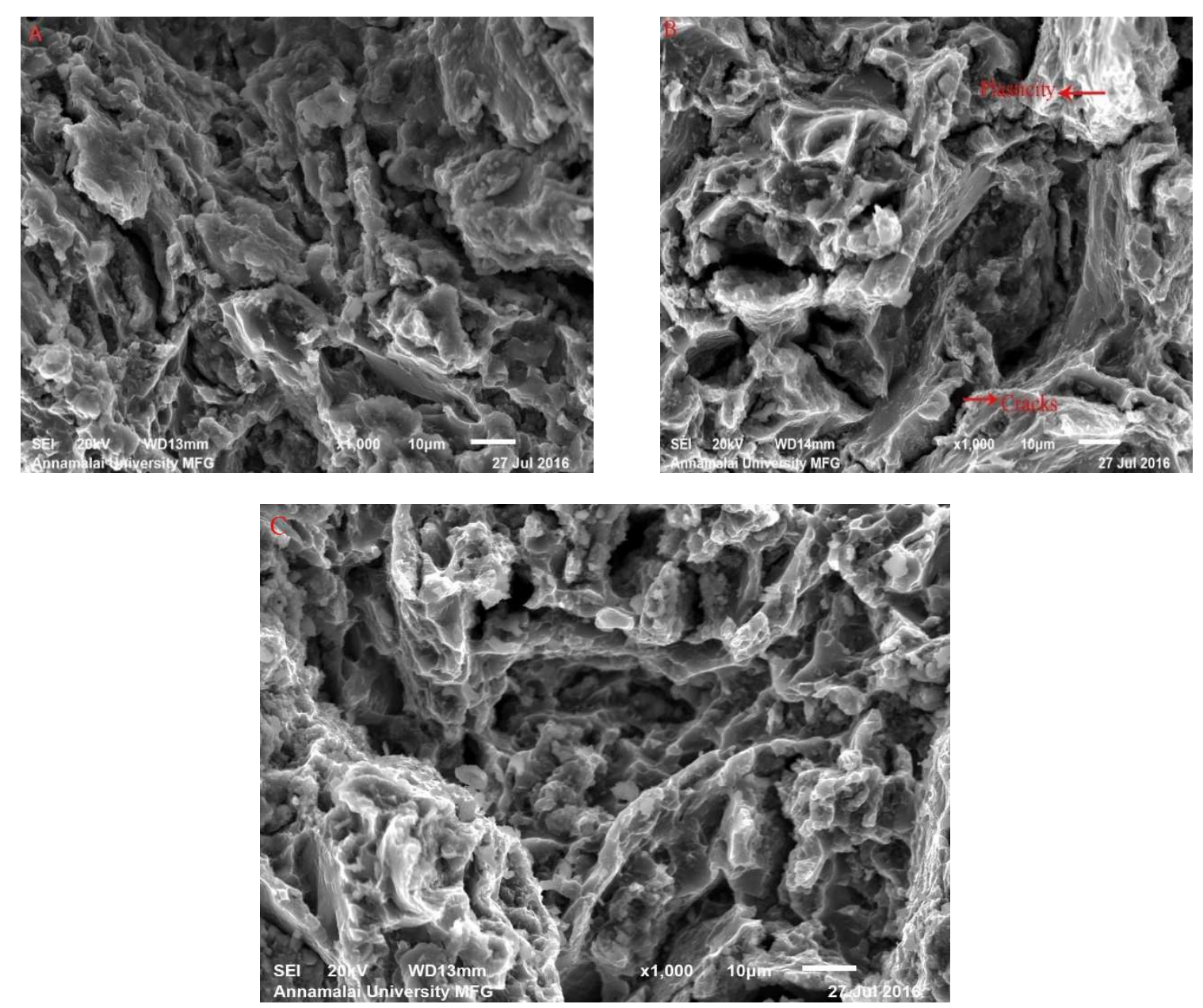

Figure 4: SEM Image of Fractured Surface of Mg-Zr alloy of Varying Sintering Temperatures (A) $450^{\circ} \mathrm{C},(B) 500^{\circ} \mathrm{C},(\mathrm{C}) 550^{\circ} \mathrm{C}$

\section{CONCLUSIONS}

- The $\mathrm{Mg}-\mathrm{Zr}$ alloy is developed by powder metallurgy process followed by hot extrusion.

- The micro structural studies manifest pores and cavities in all the microstructures.

- The increasing sintering temperature refines the crystallite size and deforms it to fill the cavities.

- When the sintering temperature increases, density, hardness, and tensile strength increase, but porosity decrease.

- Maximum density, hardness, and tensile strength result on sintering temperature $550^{\circ} \mathrm{C}$. 
- The fractured surface of Mg alloy shows quasi-cleavage fracture.

\section{REFERENCES}

1. T. Murai and S. Matsuoka and Miyamoto Y. Oki. Extrudability of Mg-Al-Zn alloys. Mater Sci Forum, 419-422:349-54, 2003. doi:10.4028/www.scientific.net/MSF.419-422.349.

2. S. Agarwal and J. Curtin and B. Duffy and S. Jaiswal. Biodegradable Magnesium Alloys for Orthopaedic Applications: A Review on Corrosion, Biocompatibility and Surface Modifications. Materials Science and Engineering: C, 68:948-63, 2016. doi:10.1016/j.msec.2016.06.020.

3. Nan Li and Yufeng Zheng. Novel Magnesium Alloys Developed for Biomedical Application: A Review. J. Mater. Sci. Technol. 29(6):489-502, 2013. doi:http://dx.doi.org/10.1016/j.jmst.2013.02.005.

4. H. Okamoto. Mg-zr (Magnesium-Zirconium). Journal of Phase Equilibria and Diffusion, 28(3):305-306, 2007. doi:10.1007/s11669-007-9060-7

5. L. Saldana and A. Mendez-Vilas and L. Jiang and M. Multigner and J.L. Gonzalez-Carrasco and M.T. Perez-Prado and M.L. Gonzalez-Martin and L. Munuera and N. Vilaboa. Biomaterials, 28:4343-4354, 2007.

6. P. Thomsen and C. Larsson and L.E. Ericson and L. Senner by and J. Lausmaa and B. Kasemo and J. Mater. Sci. Mater. Med, 8:653-665, 1997

7. N. Selvakumar and P. Ganesan and P. Radha and R. Narayanasamy and KS. Pandey. J Mater, 28(1):119-130, 2007. doi:https://doi.org/10.1016/j.matdes.2005.05.004.

8. Stevenson Archie. Heat treating of magnesium alloys. ASM Hand book, vol. 4. OH: ASM International Materials Park; 2002.

9. T.V. Padfield. "Metallography and Microstructures of Magnesium and Its Alloys, Metallography and Microstructures" Vol 9 , ASM Handbook, ASM International, 2004, p. 801-815.

10. SF. Hassan and M. Gupta. Development of a novel magnesium-copper based composite with improved mechanical properties. Mater Res Bull, 37(2):377-389, 2002, doi: https://doi.org/10.1016/S0025-5408 (01)00772-3.

11. K. Meisam and Habibi and Min Qian. Differentiating the mechanical response of hierarchical magnesium nano-composite as a function of temperature. Mater Des, 42:102-110, 2012. doi: http://dx.doi.org/10.1016/j.matdes.2012.05.037.

12. A. Daoud and MT. Abou El-Khair and M. Abdel-Aziz and P. Rohatgi. Fabrication, microstructure and compressive behaviour of ZC63 Mg-microballoon foam composites. Compos SciTechnol, 67(9):1842-1853, 2007. doi:https://doi.org/10.1016/j.compscitech.2006.10.023.

13. M. Sivapragash and PR. Lakshminarayanan and R. karthikeyan and M. Hanumantha. Bhatt RR. Hot deformation behaviour of ZE41A magnesium alloy. Mater Des, 29:860-866, 2008. doi:10.1016/j.matdes.2007.03.014. 